This is the pre-peer reviewed version of the following article: Jarimopas, B.,

Singh, S. P., Sayasoonthorn, S. and Singh, J. (2007), Comparison of package

cushioning materials to protect post-harvest impact damage to apples. Packaging

Technology and Science, 20: 315-324. doi: 10.1002/pts.760, which has been

published in final form at http://onlinelibrary.wiley.com/doi/10.1002/pts.760/abstract

\title{
Comparison of Package Cushioning Materials to Protect Post-harvest Impact Damage to Apples
}

\section{B. Jarimopas}

Department of Agricultural Engineering, Kamphaengsaen Engineering Faculty, Kasetsart University

S. P. Singh

School of Packaging, Michigan State University, East Lansing, MI, USA

\section{S. Sayasoonthorn}

The Postgraduate and Research Development Project of Postharvest Technology, Graduate School, Kasetsart University, Kamphaengsaen, Nakohnpathom, Thailand

\section{Jagjit Singh}

Industrial Technology, OCOB, Cal Poly State University, San Luis Obispo, CA 93407, USA

\section{ABSTRACT}

Damage to fruits and vegetables continues to be a big challenge as global markets become a reality. Worldwide distribution of sensitive produce is faced with various levels of impacts from shipping and handling. Despite a variety of packaging options available today, bruising damage is commonplace for post-harvest apples throughout the supply chain. The major sources of bruising are compression, impact or vibration forces. Understanding where these forces occur can help reduce this type of mechanical damage to apples. The purpose of this study was to investigate the impact characteristics of foam net and corrugated board when applied as wrapping for individual apples. Two grades (count numbers 80 and 100) of "Fuji" cultivar apples imported to Thailand from China were studied. A simple ballistic pendulum test device was developed to measure bruise volume to impact energy relationship. A linear relationship for both types of apples was observed. Bruise volume occurrence probability and impact 
energy relationship fitted by linear regression were created for cushioned and bare apples. Absorbed energy of various cushioning materials was also calculated under compressive forces.

KEY WORDS: apple; ballistic pendulum; bruise volume; cushioning; impact energy

\section{INTRODUCTION}

This study focused on developing a simple methodology to compare the performance of cushion wrapping materials that can be used for impact-sensitive fruits and vegetables. Countries such as China and India with low labor rates can use such methods to provide extreme levels of protection to fruits to compete in the global market.

Apples are a popular and nutritious horticultural product popular worldwide. Consumers insist on a high quality product that is free from any bruises, cuts, punctures, physiological disorders and pathogens. ${ }^{1}$ Bruising, which is objectionable to fresh-market consumers, can result in a lower grade for any apple. Several studies have been conducted internationally that show that compression, vibration and impact forces cause a majority of the mechanical damage, such as bruising, to apples in the supply chain.

Apples are exposed to compressive forces via forces applied by the picker's body, tree limbs, ladder rungs or rail, bulk bin rails and bottoms. Compressive forces may also get applied to apples by other apples because of excessive bulk bin depth or carton stack height, by operators forcing the cartons shut or into a tight spot, etc. ${ }^{2}$ Vibration forces are the second major cause of mechanical damage to apples in the supply chain and are almost impossible to avoid. If the cartons or bins that carry the apples through the distribution environment hit resonance (their natural frequency matches the forcing frequency of the conveyance), severe accumulated bruise damage is inherent. Impacts impart high forces in an extremely short duration and are often not obvious in mechanical handling systems such as those used in packing lines. The effect of impact forces usually results in bruises, permanent damage and lower 
perceived quality. Bruise sensitivity has also been reported to increase with storage time. ${ }^{2}$ Effectiveness of cushioning materials in protecting impact damage of apples is the primary objective of this research.

Various packaging materials are in use today to wrap individual apples to provide cushioning so that they may survive the adverse distribution environment effects. In a study, a net made of dry banana string, an agricultural waste wrapping for apples, was shown to save the fruit from damage at the impact energy of $1.1 \mathrm{~J} .^{3}$ This study mentioned problems of fungi attack due to the wrapping on the skin of the fruit. Another research studied paper that is typically applied to line the inner surface of plastic and bamboo fruit containers for protecting fresh fruit from bamboo cuts and moisture loss during transport. ${ }^{4}$ Paper was found not to be a good cushioning material against impact damage. Peleg describes good interior packaging as that which treats a fruit as separate units, avoids fruit-to-fruit contact, absorbs the impact energy and is practical. ${ }^{5}$ At present, foam nets function well as one of the commercial packaging solutions. ${ }^{6}$ However, it is not easily degradable in a landfill. ${ }^{3}$ Figure 1 shows the typical foam net used for apples.

Impact damage to apples usually materializes as bruising. ${ }^{7}$ Several researchers have studied apple bruising due to impacts. ${ }^{8-13}$ Some researches have found that an apple, when exposed to small impacts, exhibits no bruising but that noticeable bruising could be detected beyond a certain amount of impact energy. ${ }^{3,8}$ Bruises have been evaluated as bruise volume, ${ }^{12,14}$ and linear correlations have been found between the bruise volume and the impact or absorbed energy. ${ }^{8,9,15}$ Schoorl and Holt define slope of bruise volume and energy as bruise resistance. ${ }^{11}$ The threshold of apple bruising has also been studied by some researchers. Bollen et al. expressed the phenomenon of apple bruise threshold as a curve plotted between the probability of bruising against the drop height or energy. ${ }^{16}$ Some experts have credited corrugated board wrapping with adequately protecting fresh fruit from impact and compression forces. ${ }^{5,17}$ The inherent affinity of corrugated board to moisture, as with any paper-based 


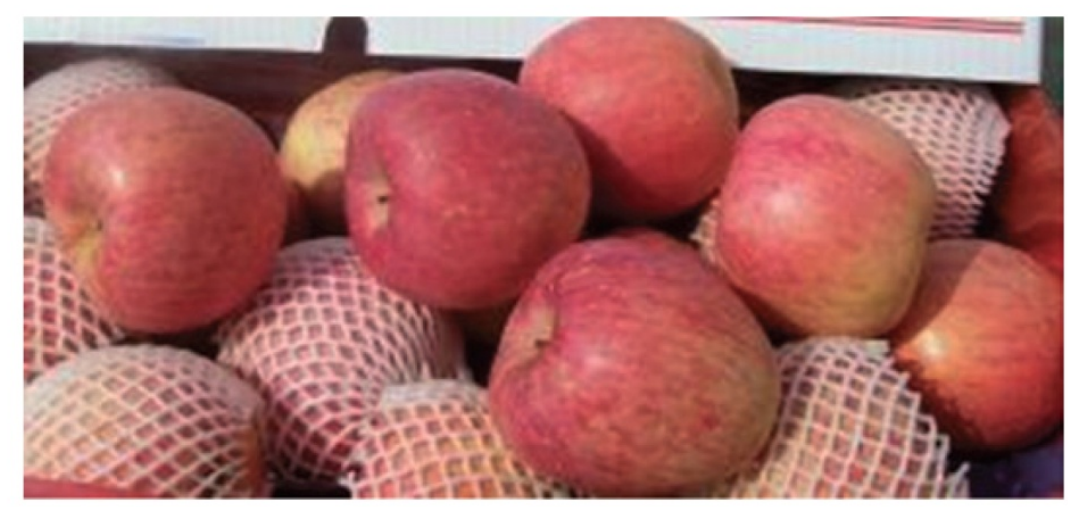

Figure 1. Foam net packaging.

packaging material, compromises its strength and cushioning capabilities. However, because of its expedient degradability, high recycling rate and low cost of the recycled paper, corrugated board holds good potential as a cushioning material. No comparative studies on physical properties of new and used corrugated board as cushioning material for wrapping fruit have ever been conducted.

Several testing devices for observing the effect of impact forces on fruits have been developed in recent years. These instrumented devices are generally capable of measuring acceleration, force, displacement, time and contact area during impact. ${ }^{10,18-20}$ Some of these devices are capable of recording, processing and storing impact data during the experimentation. ${ }^{21,22}$ By using these instrumented devices, measurements can be achieved instantly and accurately, but at a very high expense. Often times, a majority of the capabilities of such devices are not utilized, and accurate measurements of impact parameters such as impact and absorbed energy can be made using a simple and affordable device that provides sufficient repeatability and reproducibility.

The main objectives of this study were as follows:

1. Develop a simple ballistic pendulum-type test fixture operable by one person that provides a high sensitivity of energy settings and dependable energy-bruise volume measurements.

2. Compare the impact-absorbing characteristics of the bare apples to apples that are wrapped 
with various cushioning materials.

3. Recommend best materials and wrapping orientation for protecting against impact forces.

\section{MATERIALS AND METHODS}

\section{Apples}

"Fuji" cultivar apples imported from China to Thailand without any physical injury were used for the testing because the bruising discoloration of this apple is easily detected, and it is available in Thailand markets. Two sizes of the apple were used: count number 80 (fruit weight $=240 \pm 20 \mathrm{~g}$ ) and number 100 (fruit weight $=180 \pm 20 \mathrm{~g}$ ).

\section{Simple instrumented pendulum}

An impact testing device was designed to be a ballistic pendulum featuring $3.84 \mathrm{~kg}$ rectangular steel mass hung by four $45 \mathrm{~cm}$ long ropes like a cradle (Figure 2). The motion of the pendulum mass was curvilinear translation. A laser pointer, mounted at the back of the mass, projects a beam to mark a 1 $\mathrm{mm}$ red circle on a scale (each graduation is equivalent to $7.5 \mathrm{~mm} /$ degree of motion) $15 \mathrm{~cm}$ under the mass. This facilitates the setting of incident angle and impact energy. Pivot points of the rope at four corners of the mass were set on the same horizontal plane, passing a fulcrum providing stable motion without excessive swinging. An apple sample was placed in the sample holder with a pin plugged into the top of the fruit. There was a small rope placed perpendicular to the pendulum motion plane that connected to the pin in order to prevent the sample from falling down after the impact, thereby avoiding any unwanted mechanical injuries. The testing device was operated by a single person and proved to give higher sensitivity of energy setting and better energy-bruise volume curve fitting compared with the pendulum without instrumentation. ${ }^{23}$ 


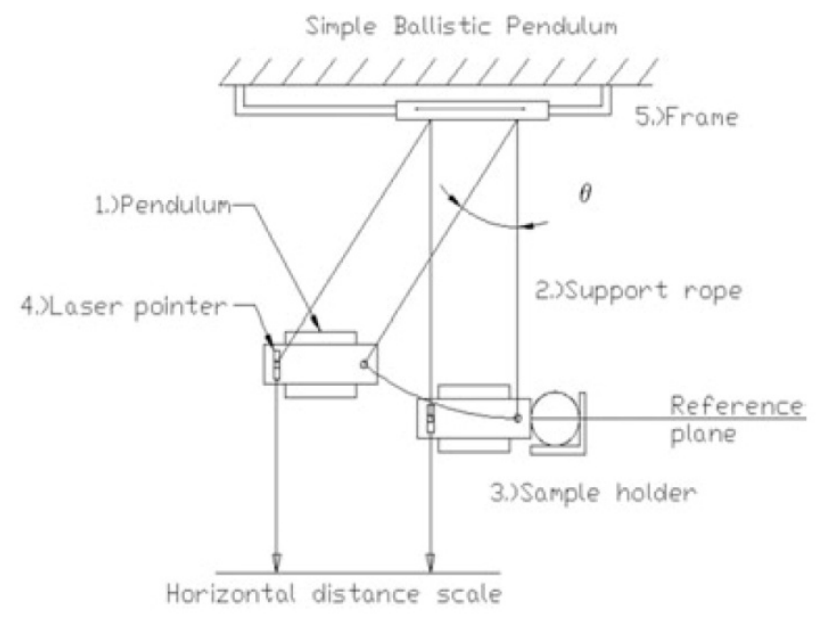

Figure 2. A schematic diagram of the simple ballistic pendulum.

\section{Cushioning wrapping materials}

Two types of cushioning material were used to comparatively test their protective performance. A $2 \mathrm{~mm}$ thick typical apple foam net (Figure 3) and corrugated board were used as wrapping for individual apples. Four types of the corrugated board wrapping were used:

- Single face with corrugated medium outside (SFO)

- Single face with corrugated medium inside (SFI)

- New double-wall corrugated board (NDW)

- Used double-wall corrugated board (UDW)

For the NDW and UDW, $240 \times 80 \mathrm{~mm}$ each, the flutes ran parallel to the length of the wrapping. To facilitate bending when wrapping the corrugated board around the fruit, small perforations across the width giving $3 \mathrm{~mm}$ wide strips were made (Figure 4).

To cushion an apple sample, foam net was directly put on it while the sheet of each type of the corrugated board had to be wrapped around the fruit with the sheet edges touching each other. 


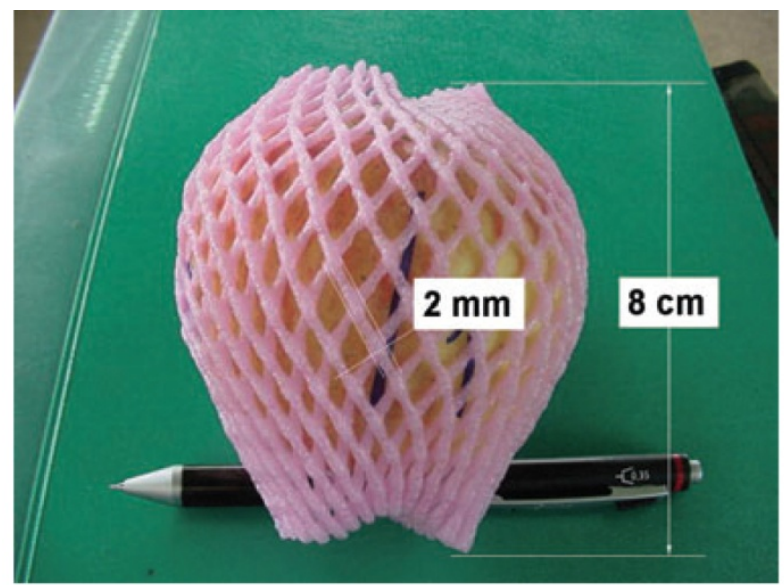

Figure 3. Foam net wrapping.

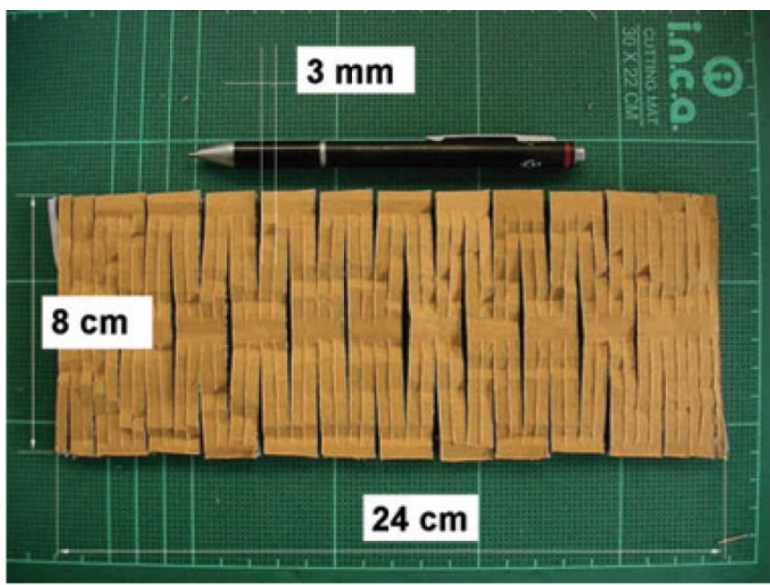

Figure 4. Corrugated board.

\section{EXPERIMENTAL DESIGN}

\section{Impact test}

The experimental design consisted of two apple sizes tested with and without the five types of cushioning materials. Mechanical behaviours of concern were bruise volume and 20 levels of impact energy $(0.04-0.75 \mathrm{~J})$ for bruise volume and to impact energy threshold determination and 10 levels of impact energy (0.02-2.0J) for bruise volume to impact energy relationship beyond threshold.

The cushioned apple was mounted at the sample holder, and desired impact energy was located on the scale by the pointer. The pendulum was then released to impact the sample from the corresponding release angle. Bruise volume and the related impact energy were then recorded. Ten replications were conducted for each bruise volume to impact energy threshold and five replications were made for each determination of bruise volume to impact energy beyond threshold. Impact energy was calculated from the following equation:

$$
E=m g R\left(1-\cos \theta_{i}\right)
$$

where $E$ is the impact energy $(\mathrm{J}) ; m$ is the mass of the pendulum $(\mathrm{kg})$; $\mathrm{g}$ is the gravitational constant 
$\left(9.81 \mathrm{~m} / \mathrm{s}^{2}\right) ; R$ is the length of the hanging rope $(\mathrm{m})$; and $\theta_{i}$ is the angle of incidence (degree).

After the impact, the apples were stored for $24 \mathrm{~h}$ at room temperature to allow the browning/discoloration to become more apparent. After this period, the apples were sectioned at the contact area. Bruise volume was calculated as follows:

$$
V=(\Pi / 8) w^{2} d
$$

where $V$ is the bruise volume; $w$ is the width of the bruise $(\mathrm{mm})$; and $d$ is the depth of the bruise $(\mathrm{mm})$.

The probability of bruising was calculated using the following equation:

$$
\begin{gathered}
\text { Probability of bruise } \\
\text { volume occurrence }
\end{gathered}=\frac{\begin{array}{c}
\text { Number of } \\
\text { non-zero bruises }
\end{array}}{\begin{array}{c}
\text { Number of replications } \\
\text { of the same treatment }
\end{array}}
$$

\section{Compression test}

Compression testing for all samples was conducted as per the TAPPI (Technical Association of Pulp and Paper Industry) T 808 standard. Ten samples of each cushioning material were cut into $32.2 \mathrm{~cm}^{2}$ circular pieces and compressed between two parallel flat platens of an Instron Universal Testing Machine (model 5569, Instron Corporation, Norwood, MA, USA) at a crosshead speed of $12.5 \mathrm{~mm} / \mathrm{min}$ to determine the flat crush strengths. Forces versus deflection values were recorded. A computer program was then used to calculate the area under the curve as an absorbed energy.

\section{RESULTS AND DISCUSSION}

\section{Bruise volume to impact energy beyond threshold relationship}

Figures 5 and 6 below show the results as bruise volume to impact energy relationships for both 
types of apples.

The bruise volume, $\mathrm{V}$, linearly increases with the energy, $\mathrm{E},\left(R^{2} \geq 0.93\right)$ for both sizes of apples. These findings agree with previous studies..$^{8,9,11,15}$

For a certain applied energy, a smaller bruise volume was observed with the cushioned apple of lower lines. A small bruise volume for bare apples corresponds to small impact energy. This is true for the cushioned apples as well. The lower bruise volumes of the impacted cushioned apples with respect to the bare apples was a result of a very small fraction of the impact energy being transferred through the cushioning material to the apples while a large fraction of impact energy was absorbed by the cushioning material. The impact of the pendulum caused bruising on the contact face. Besides, bruising occurred on the opposite side of the fruit of the other contact because of compression resulting from

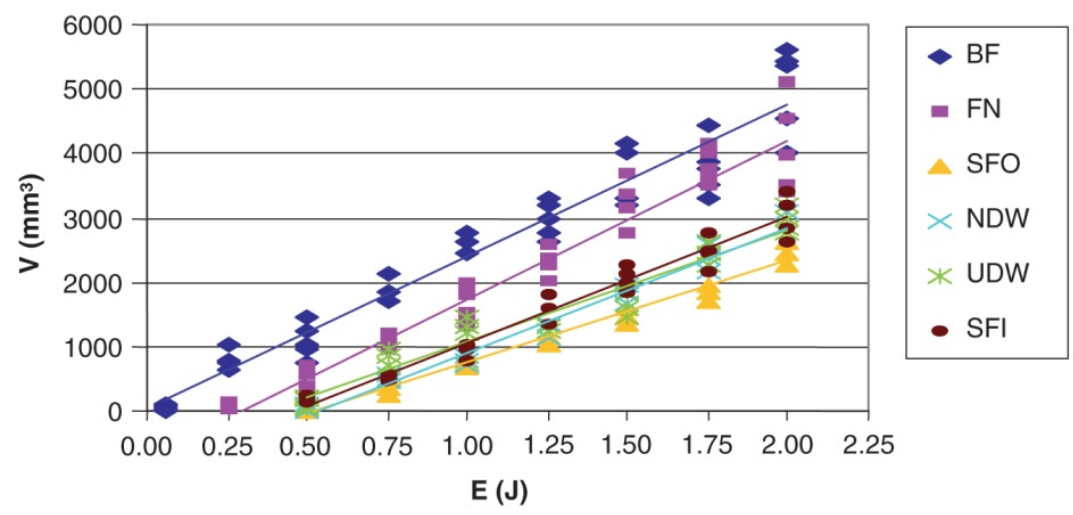

Figure 5. Bruise volume versus impact energy beyond threshold relationship for $180 \mathrm{~g}$ apples. BF, bare fruit; FN, foam net; NDW, new double-wall corrugated board; SFI, single face corrugated board with flute on the inside; SFO, single face corrugated board with flute on the outside; UDW, used double-wall corrugated board.

the impact. The bruise volume of the backside seemed to be less than that of the front side because of less compression due to absorbed impact energy. Table 1 shows the bruise volume to impact energy 


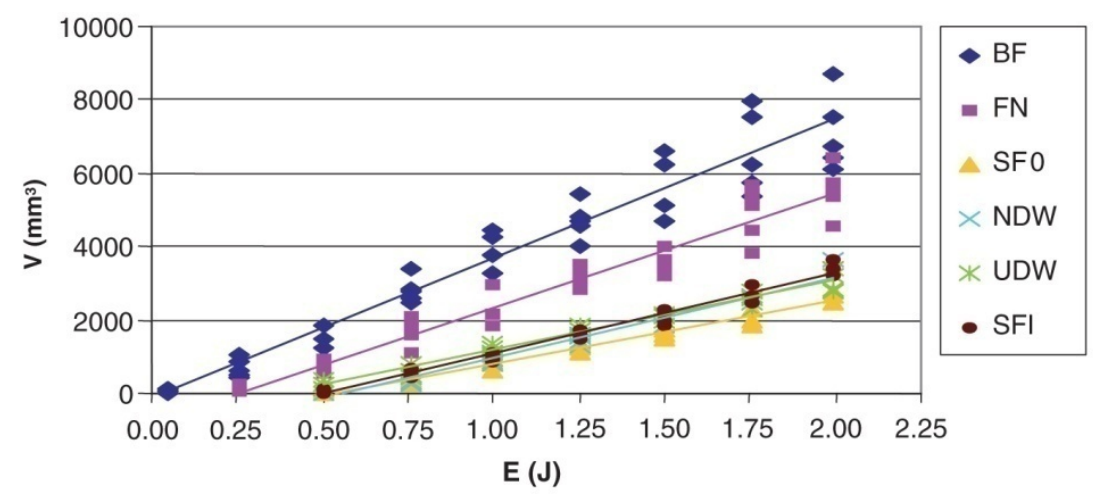

Figure 6. Bruise volume versus impact energy beyond threshold relationship for $240 \mathrm{~g}$ apples.

\begin{tabular}{|c|c|c|c|c|}
\hline \multirow{2}{*}{$\begin{array}{l}\text { Cushioning } \\
\text { material }\end{array}$} & \multicolumn{4}{|c|}{ Equation of relationship } \\
\hline & $180 \mathrm{~g}$ apples & $R^{2}$ & $240 \mathrm{~g}$ apples & $R^{2}$ \\
\hline SFO & $V=1595.3 E-854.26$ & 0.98 & $V=1748.1 E-945.93$ & 0.98 \\
\hline UDW & $V=1741.5 E-663.97$ & 0.93 & $V=1877.5 E-682.14$ & 0.97 \\
\hline NDW & $V=1946.9 \mathrm{E}-1051.1$ & 0.97 & $\mathrm{~V}=2179.4 \mathrm{E}-1196.3$ & 0.97 \\
\hline $\mathrm{SFI}$ & $V=1960.1 E-905.99$ & 0.96 & $V=2188.1 E-1117$ & 0.98 \\
\hline FN & $V=2465.6 \mathrm{E}-732.95$ & 0.93 & $\mathrm{~V}=3|| 3.2 \mathrm{E}-772.83$ & 0.94 \\
\hline $\mathrm{BF}$ & $V=2350 E+62.415$ & 0.94 & $\mathrm{~V}=3812.5 \mathrm{E}-145.18$ & 0.93 \\
\hline
\end{tabular}

linear expression of the cushioned apples of both sizes. Schoorl and Holt defined the slope of bruise volume to impact energy regression lines as bruise resistance of the impacted material and apples. ${ }^{11}$ This implies that the lower slope, derived from a small bruise volume over high impact energy, is considered to have a higher bruise resistance than those materials with high bruise volumes over small impact energy (having a high slope). The foam net for which the slope was $\left(2466 \mathrm{~mm}^{3} / \mathrm{J}\right)$ steeper than that for bare apples $\left(2350 \mathrm{~mm}^{3} / \mathrm{J}\right)$ exhibited a lower bruise volume than that for the bare fruit. This indicates that the bruise resistance defined by the slope is perhaps invalid. Such definition would probably be possible if the origin of all the bruise volume to impact energy fitted graphs was at the same point. But bruise volume to impact energy graphs of the cushioned apple are affected by threshold energy so that their 
origin $(\mathrm{V}=0)$ are different. The bruise volume to impact energy relationship beyond the threshold is then insufficient to explain the bruise resistance or protective performance of the cushioning materials of apple.

\section{Bruise volume to impact energy relationship below and at threshold}

Figures 7 and 8 show the relationship between the probability of bruise volume occurrence and the associated impact energy. Bollen et al. used the graph of probability versus impact energy to identify the threshold of apples. ${ }^{16}$ There are six linear regression graphs $\left(R^{2} \geq 0.88\right)$ corresponding to five cushioning materials and bare fruit as tested using the simple pendulum device. The bruise volume of an apple or cushioned apple can be estimated at various levels of impact energy. The greater the impact energy a cushioned apple received, the higher the bruise occurrence probability was. At the levels where probability is equal to one, the impact energy is estimated to definitely cause bruising. This is called the threshold level.

Table 2 shows threshold energy for the cushioned and bare apples. The cushioned apples could bear a higher impact energy than the bare apple. This is because of the cushioning material acting as a shield

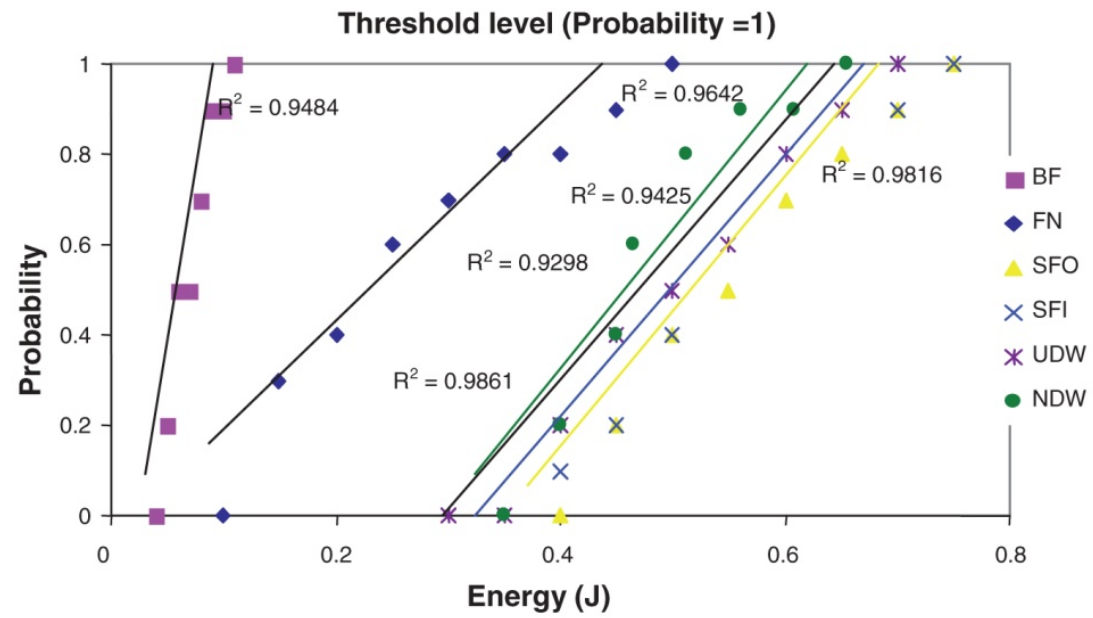

Figure 7. Bruise occurrence probability and impact energy relationship fitted by linear regression of various cushioned and bare $180 \mathrm{~g}$ apples. 


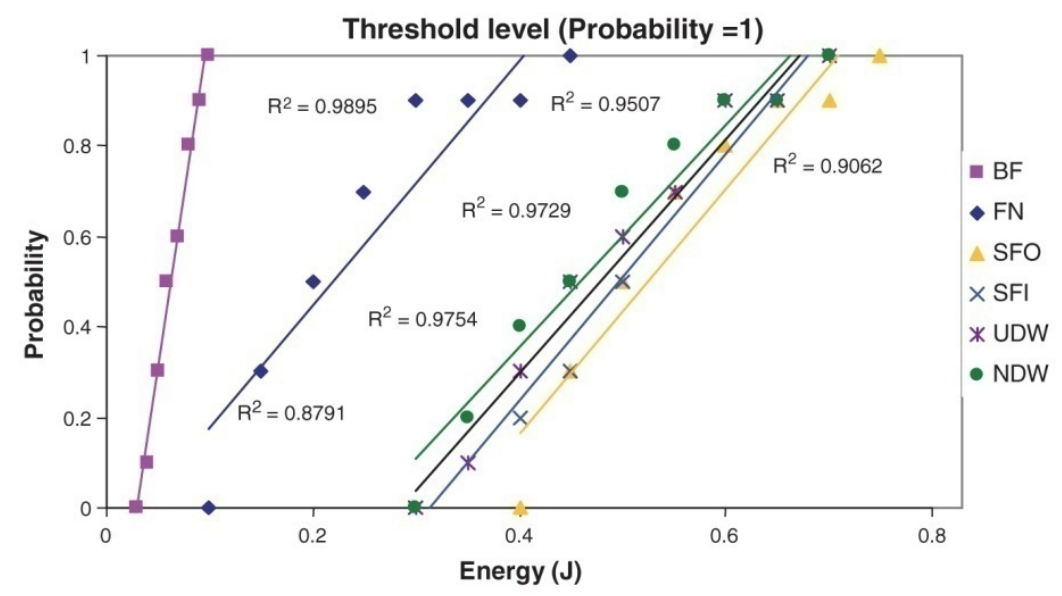

Figure 8. Bruise occurrence probability and impact energy relationship fitted by linear regression of various cushioned and bare $240 \mathrm{~g}$ apples.

\begin{tabular}{|c|c|c|c|}
\hline \multirow[b]{3}{*}{ Cushioning material } & $\begin{array}{l}\text { olume and } \\
=1 \text { ) of cus }\end{array}$ & $\begin{array}{l}\text { act energy } \\
\text { led and ba! }\end{array}$ & $\begin{array}{l}\text { threshold } \\
\text { pples }\end{array}$ \\
\hline & \multicolumn{2}{|c|}{ Average bruise volume $\left(\mathrm{mm}^{3}\right)$} & \multirow{2}{*}{$\begin{array}{l}\text { Apple threshold } \\
\text { energy* (J) }\end{array}$} \\
\hline & $180 \mathrm{~g}$ apples & $240 \mathrm{~g}$ apples & \\
\hline SF0 & $280 \pm 50$ & $307 \pm 60$ & 0.75 \\
\hline UDW & $379 \pm 70$ & $398 \pm 45$ & 0.70 \\
\hline NDW & $4 I I \pm 55$ & $424 \pm 60$ & 0.70 \\
\hline & $419 \pm 25$ & $453 \pm 50$ & $0.725 \pm 0.026$ \\
\hline $\mathrm{FN}$ & $447 \pm 50$ & $481 \pm 50$ & $0.475 \pm 0.026$ \\
\hline BF & $161 \pm 30$ & $165 \pm 40$ & $0.105 \pm 0.005$ \\
\hline \multicolumn{4}{|c|}{$\begin{array}{l}\text { *Threshold energy for a certain cushioning between the two groups of apples ( } 180 \text { and } \\
240 \text { g) was insignificantly different at the confidence level of } 99 \% \text {. BF, bare fruit; FN, foam } \\
\text { net; NDW, new double-wall corrugated board; SFI, single face corrugated board with flute } \\
\text { on the inside; SFO, single face corrugated board with flute on the outside; UDW, used } \\
\text { double-wall corrugated board. }\end{array}$} \\
\hline
\end{tabular}

absorbing a fraction of the impact energy and transferring the rest to the apple. If the absorbed energy, $E_{a}$, is small and the remaining fraction to impact apple, $E_{R}$, is high, the cushioning material is rendered less effective and the threshold impact energy, $E_{t h}$, turns out to be low. On the other hand if $E_{a}$ is large and $E_{R}$ is low, $E_{t h}$ tends to be high and the cushioning material is fairly protective. The corresponding cushioned apples exhibited high bruise resistance. In this research, the single-face corrugated board wrapping with the flutes on the outside are concluded to be the most protective, giving the highest $E_{t h}$ 
(0.75J) for both sizes of apples. The threshold energy for a certain cushioning material between the two groups of apples (180 and 240g) was insignificantly different at the confidence level of $99 \%$.

\section{Absorbed energy of the cushioning materials}

Table 3 provides the absorbed energy from the force-deflection response of each cushioning material under quasi-static compression. The absorbed energy of the single face corrugated board with flutes on the outside is relatively high $(0.11 \mathrm{~J})$, indicating that it could absorb higher impact energy than other cushioning materials and release the least remaining fraction to the apple, resulting in the smallest bruise to the apples (Table 2). Figure 9 shows the contact orientation of the single face corrugated board to the apples.

\begin{tabular}{|lc|}
\hline $\begin{array}{c}\text { Table 3. Absorbed energy of cushioning } \\
\text { materials under quasi-static compression }\end{array}$ \\
Cushioning material & Absorbed energy (J) \\
\hline SF0 & $0.110 \pm 0.012$ \\
UDW & $0.090 \pm 0.008$ \\
NDW & $0.094 \pm 0.008$ \\
SFI & $0.110 \pm 0.012$ \\
FN & $0.075 \pm 0.008$ \\
FN, foam net; NDW, new double-wall corrugated board; SFI, \\
single face corrugated board with flute on the inside; SFO, single \\
face corrugated board with flute on the outside; UDW, used \\
double-wall corrugated board. \\
\hline
\end{tabular}
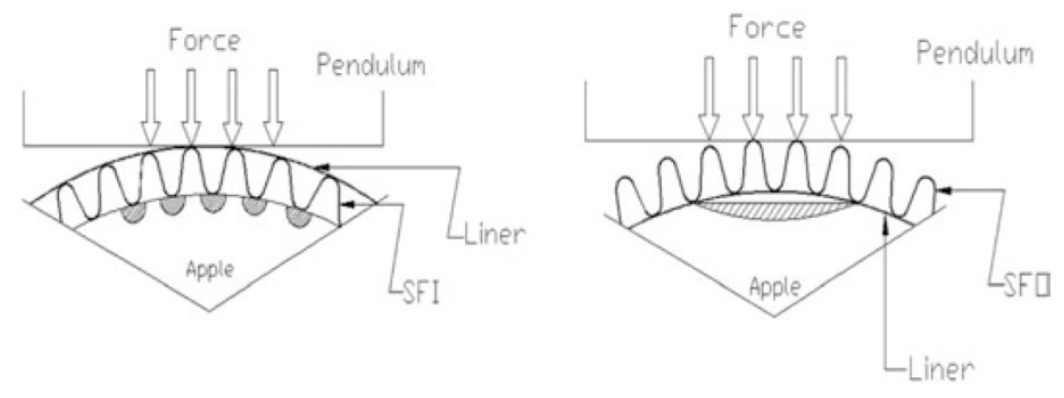

Figure 9. Contact orientation between single face corrugated board to the wrapped apple. 
The single face corrugated board with flutes on the outside gave one contact point, lying in the impact line, with the apple surface, while the single face corrugated board with flutes on the inside exhibited several contact points over the contact area because of the flute contact with the apples. This created greater contact pressure over the small contact points, hence giving rise to bigger bruise volumes. Even though the absorbed energies for both the single face corrugated board orientations are the same, the difference in the contact orientation between the single face corrugated paper and wrapped apple surface differentiated the bruise volume and bruise volume pattern.

\section{CONCLUSIONS}

This study evaluated the various types of protective cushioning systems that can be used directly on fruits such as apples to reduce bruise injury resulting from post-harvest and transportation to retailers. The study developed a simplified test method that can be used to measure impact resistance strength characteristics of apples or other fruits, and evaluate cushioning materials that can provide shock

protection. Both plastic and paper based protective wraps can be effective in providing against bruising from impacts. Results show that the best protection was achieved with the single face corrugated board with flutes on the outside. Threshold energy for a certain cushioning was insignificantly different between the two sizes of apples.

\section{ACKNOWLEDGEMENTS}

The authors would like to acknowledge the Postgraduate and Research Development Project of Postharvest Technology at Chiang Mai University and National Metal and Materials Technology Center (MTEC) for their financial support. Further thanks to Prof. P. Chen, Professor Emeritus, Department of Agricultural and Biological Engineering, University of California, Davis, for his valuable guidance. 


\section{REFERENCES}

1. Matzinger B, Tong C. Commercial Postharvest Handling of Fresh Market Apples (Malus sp.), University of Minnesota, Extension Service: MN. 1993.

2. Brown GK, Schulte NL, Timm EJ, Armstrong PR, Marshall DE. Reduce apple bruise damage. Tree Fruit Postharvest J. 1993; 4(3): 6-10

3. Jarimopas B, Mahayosanan T, Srianek N. Study of capability of net made of banana string for apple protection against impact. Eng. J. Kasetsart. 2004; 17(51): 9-16.

4. Jarimopas B, Robchanachon J, Surin R. Study of wholesale package for fruits and vegetables in Bangkok metropolitan area. Thai Society of Agricultural Engineering Journal. 2002; 9(2): 23-28.

5. Peleg K. Produce Handling, Packaging and Distribution. AVI Publishing Company Inc.: Connecticut, 1985.

6. Chonhenchob V, Singh SP. Testing and comparison of various packages for mango distribution. J. Test. Eval. 2004; 32(1): 69-72.

7. Bollen AF, Nguyen HX, Dela Rue BT. Comparison of methods for estimating the bruise volume of apples. J. Agri. Eng. Res. 1999; 74: 325-330.

8. Jarimopas B. Failure of apple under dynamic loadings. Unpublished D.Sc. Dissertation, Faculty of Agricultural Engineering, Technion, Israel Institute of Technology, 1984.

9. Holt JE, Schoorl D. Bruising and energy dissipation in apples. J. Texture Studies. 1977; 7: 421-432.

10. Bajema RW, Hyde GM. Instrumented pendulum for impact characterization of whole fruit and vegetable specimens. Trans. Am. Soc. Agri. Eng. 1998; 41(5): 1399-1405. 
11. Schoorl D, Holt JE. Bruise resistance measurements in apples. J. Texture Studies. 1980; 11: 389-394.

12. Chen P, Yazdani R. Prediction of apple bruising due to impact on different surfaces. Trans. Am. Soc. Agri. Eng. 1991; 34(3): 956-961.

13. Ragni L, Berandinelli A. Mechanical behavior of apples and damage during sorting and packaging. J. Agri. Eng. Res. 2001; 78(3): 273-279.

14. Mohsenin NN. Physical Properties of Plant and Animal Materials. Gordon and Breach Publishers: Bangkok, Thailand, 1996.

15. Ruiz Altisent M. Damage mechanisms in the handling of fruits. In Progress in Agricultural Physics and Engineering, Matthews J (ed.). Silsoe Research Institute C.A.B International: Oxon, UK, 1991; 231-257.

16. Bollen AF, Cox NR, Dela Rue BT, Painter DJ. A descriptor for damage susceptibility of a population of produce. J. Agri. Eng. Res. 2001; 78(4): 391-395.

17. Thailand Institute of Scientific and Technological Research (TISTR). Handbook of Paper Application for Packaging (in Thai). Arun Printing Co. Ltd.: Bangkok, 2002.

18. Jarimopas B, Sarig Y, Peiper UM, Manor G. Instrumentation for measuring the response of apples subjected to impact loading. Comp. Elec. Ag. 5(1990): 255-260.

19. Chen $\mathrm{P}$, Tang $\mathrm{S}$, Chen S. Instrument for testing the response of fruits to impact. American Society of Agricultural Engineers Paper No. 85-3537 1985. ASAE: St. Joseph, MI, 1985.

20. Lichtensteiger MJ, Holmes RG, Hamdy MY, Blaisdell JL. impact parameters of spherical viscoelastic object and tomatoes. Trans. Am. Soc. Agri. Eng. 1988; 31(2): 595-602. 
21. Siyami S, Tennes BR, Zapp HR et al. Microcontroller based data acquisition system for impact measurements. Trans. Am. Soc. Agri. Eng. 1987; 30(6): 1822- 1826.

22. Tennes BR, Zapp HR, Brown GK, Elhert SH. Selfcontained impact detection device. calibration and accuracy. Trans. Am. Soc. Agri. Eng. 1988; 31(6): 1869-1874.

23. Jarimopas B, Sayasoonthorn S. Improvement of ballistic pendulum impact testing device. Thai Society of Agricultural Engineering Journal. 2004; 11(1): 51-56.

24. Jarimopas B. Postharvest Sorting Machinery, Packaging and Packing House of Fruit Thai Society of Agricultural Engineering, Bangkok, 2006, 216 p. 